\section{Terakreditasi}

Ditjen Penguatan Riset dan Pengembangan, Kemenristekdikti

Keputusan No: 21/E/KPT/2018, Tanggal 9 Juli 2018
Mei 2019, 6(2):283-287

DOI: http://dx.doi.org/10.33772/jitro.v6i2.5857

http://ojs.uho.ac.id/index.php/peternakan-tropis

\title{
Pengaruh Jarak Tanam pada Pertumbuhan Beberapa Varietas Sorgum Hybrid Sebagai Sumber Pakan
}

\author{
Hajar $^{1)}$, Luki Abdullah ${ }^{2}$, Didid Diapari ${ }^{2)}$ \\ ${ }^{1)}$ Mahasiswa Magister Ilmu Nutrisi dan Pakan, Institut Pertanian Bogor \\ ${ }^{2)}$ Departemen Ilmu Nutrisi dan Pakan, Fakultas Peternakan, Institut Pertanian Bogor \\ J1. Agatis, Kampus IPB Darmaga, Bogor 16680 \\ *Email korespondensi: hajarliya1993@gmail.com
}

(Diterima: 11-03-2019; disetujui 30-04-2019)

\begin{abstract}
ABSTRAK
Penelitian ini bertujuan untuk mengevaluasi pertumbuhan pada beberapa varietas sorgum hybrid, serta menetapkan jarak tanam yang optimal pada tanaman sorgum. Penelitian ini dilaksanakan di Laboratorium Lapangan Agrostologi Fakultas Peternakan IPB. Perlakuan dalam penelitian ini disusun secara faktorial (3x2) dalam Rancangan Acak Kelompok (RAK) dengan 6 perlakuan dan empat ulangan. Faktor pertama adalah varietas 12FS9006, 13FB7001 dan 12S49001. Faktor kedua adalah jarak tanam $25 \times 25 \mathrm{~cm}$ dan $25 \times 40 \mathrm{~cm}$. Hasil penelitian menunjukan varietas sorgum berpengaruh sangat nyata $(\mathrm{P}<0,05)$ terhadap tinggi tanaman, diameter-2 batang, lebar, panjang dan jumlah daun. Interaksi antara varietas dan jarak tanam tidak berpengaruh terhadap pertumbuhan. Demikian dengan jarak tanam tidak memberikan pengaruh nyata. Kesimpulan varietas 12S49001 memiliki pertumbuhan tanaman yang paling tinggi dan jarak tanam optimun $25 \times 25 \mathrm{~cm}$. Varietas yang unggul ada pada varietas 12S49001 sebaiknya dikembangkan sebagai pakan ternak.
\end{abstract}

Kata Kunci: jarak tanam, pertumbuhan, varietas hybrid.

\section{ABSTRACT}

Thiese reseach aim was to evaluate growth of hybird sorghum varieties and well as establish the most ideal spacing on sorghum plants. This study was conducted in Agrostology Laboratorium Animal Science Faculty IPB. This study was arranged by $3 \times 2$ factorial in block randomized block design (RBD) with six treatments and four replications. The first factor was the varieties 12FS9006, $13 F B 7001$ and 12S49001 varieties. The second factor was spac of $25 \times 25 \mathrm{~cm}$ and $25 \times 40 \mathrm{~cm}$. The result showed sorghum varieties was significantly different $(\mathrm{P}<0,05)$ on plant height, stem diameter, width, length and number of leaves. Interaction between variety and plant spacing was not significantly on growth, so as plant spacing was not significantly. It concluded the highest growth of sorghum varieties $12 \mathrm{~S} 49001$ and spac $25 \times 25 \mathrm{~cm}$ was the best plan spac for hybrid sorghum.

Keywords: hybrid varieties, growth, spacing

\section{PENDAHULUAN}

Hijauan merupakan sumber pakan bagi ternak ruminansia, baik untuk kehidupan pokok, pertumbuhan, produksi dan reproduksi ternaknya. Hijauan memiliki peran yang penting, karena hijauan mengandung zat-zat makanan yang dibutuhkan oleh ternak ruminansia, sehingga untuk mencapai produktivitas yang optimal di tunjang dengan penyediaan hijauan pakan yang cukup baik kualitas, kuantitas maupun kontinuitasnya.
Salah satu jenis hijauan yang dikonsumsi oleh ternak ruminansia adalah sorgum (Sorghum bicolor (L.) Moench). Sorgum merupakan kelompok graminae atau rumput-rumputan. Hijauan ini dikenal sebagai salah satu jenis hijauan yang tahan pada lahan marginal, serta relatif tahan terhadap gangguan hama maupun penyakit (Sirappa, 2003; Barcelos et al., 2016).

Salah satu upaya dilakukan untuk menjamin produktivitas dan ketersediaan pakan hijauan dengan cara introduksi atau pengenalan varietas baru tanaman sorgum. Penelitian 
sebelumnya (Blummel et al., 2003) menyatakan varietas sorgum atau introduksi sebagai pakan ternak sangat berpotensi terhadap peningkatan hijauan pakan. Introduksi varietas sorgum baru memiliki beberapa manfaat diantaranya menambah keragaman varietas sorgum di Indonesia untuk pakan, sebagai bahan persilangan, atau langsung dilepas sebagai varietas setelah diuji adaptasi (Syukur et al., 2012).

Selain pengenalan varietas baru yang dilakukan, ada upaya lain dengan pengaturan jarak tanam. Jarak tanam merupakan faktor penting untuk teknik penanaman tanaman karena mempengaruhi populasi tanaman dan produksi yang dihasilkan. Pengaturan jarak tanam sangat berkaitan dengan pertumbuhan dan produksi dalam satuan luasan dan jumlah hasil yang akan diperoleh dalam satuan luas tertentu (Helena, 2000).

Beberapa kelebihan varietas sorgum hybrid untuk pakan ternak yaitu varietas sorgum hybrid 12S49001 adalah memiliki pertumbuhan tergolong tinggi dan produksi biomassa yang tinggi. Varietas sorgum hybrid 12FS5006 adalah memiliki pertumbuhan tergolong tinggi dan produksi biji yang tinggi. varietas sorgum hybrid 13FB7001 adalah memiliki ukuran batang yang lebar dan produksi daun lebih tinggi (Dwitama, 2017).

Berdasarkan uraian pada latar belakang maka penelitian ini diharapkan mampu menghasilkan hijauan bersumber energi yang berkualitas baik. Memberikan informasi kepada peternak untuk membudidayakan tanaman sorgum sebagai pakan ternak mulai dari varietas tanaman hingga jarak tanam. Menambah informasi ilmiah tentang kajian mengenai pertumbuhan sorgum hybrid sebagai sumber pakan.

\section{MATERI DAN METODE}

\section{Materi Penelitian}

Penelitian ini dilakukan pada bulan November 2017 sampai Januari 2018. Penelitian ini dilaksanakan di Laboratorium Lapang Agrostologi Fakultas Peternakan IPB.

Alat yang digunakan dalam penelitian ini adalah meteran, jangka sorong, hack tractor mini, dan timbangan. Bahan yang digunakan bibit sorgum varietas hybrid 12FS5006, varietas 13FB7001 dan varietas 13S49001, pupuk kandang (feses sapi), NPK dan kapur dolomit.

\section{Metode Penelitian \\ Persiapan lahan; pengambilan sampel tanah, dilakukan pembajakan untuk} memecahkan bongkahan tanah, selanjutnya dilakukan pemupukan kandang, pengapuran, dan pencangkulan sebelum penanaman.

Penanaman; empat belas hari setelah pengolahan tanah dilakukan penanaman bibit ditanam pada petakan berukuran $4 \mathrm{~m}$ x $4 \mathrm{~m}$ dengan jarak tanam yaitu $25 \times 25 \mathrm{~cm}$ dan $25 \times 40$ $\mathrm{cm}$. Setelah berusia 21 hari dipupuk menggunakan pupuk NPK.

Pemeliharaan; pemeliharaan dilakukan dengan penyiraman dua kali sehari dan pembersihan gulma pada plot penanaman.

Pengamatan; pengamatan dilakukan tiap minggu sampai umur 95 hari. Penelitian dilaksanakan dengan percobaan lapangan faktorial 3 x 2 dengan 4 kali ulangan disusun dengan rancangan acak kelompok. Faktor pertama adalah varietas sorgum hybrid yang terdiri dari varietas 12FS5006, varietas 13FB7001, dan varietas 13S49001. Faktor kedua adalah jarak tanam $25 \times 25 \mathrm{~cm}$ dan $25 \mathrm{x}$ $40 \mathrm{~cm}$.

\section{Peubah dan Rancangan Penelitian}

Variabel yang diamati meliputi tinggi tanaman $(\mathrm{cm})$, diameter batang $(\mathrm{cm})$, lebar daun $(\mathrm{cm})$, panjang daun $(\mathrm{cm})$ jumlah daun (helai). Data dianalisis menggunakan sidik ragam. Apabila perlakuan berpengaruh nyata, maka dilanjutkan dengan uji Tukey. Analisis data dilakukan menggunakan software statistik SAS 9.4. Pengujian dilakukan pada taraf nyata $5 \%$ dan $1 \%$.

\section{HASIL DAN PEMBAHASAN}

\section{Tinggi dan Diameter Batang}

Tinggi tanaman dan diameter batang merupakan salah satu pengamatan yang digunakan untuk mengetahui kuantitas biomassa pada tanaman (Sriagtula et al., 2017). Tinggi dan diameter batang disajikan pada Tabel 1. Interaksi antara varietas sorgum hybrid dan jarak tanam tidak berpengaruh terhadap tinggi tanaman. Varietas sorgum berpengaruh nyata $(\mathrm{P}<0,05)$ terhadap tinggi tanaman. Varietas sorgum hybrid yang tertinggi ada pada varietas 12S49006 $(203,05 \mathrm{~cm})$ dan 12FS9006 $(184,75 \mathrm{~cm})$.Varietas memiliki tinggi terendah terdapat pada varietas 13 FB7001 $(163,85 \mathrm{~cm})$. Hal ini diduga bahwa varietas $12 \mathrm{~S} 49006$ 
memiliki pertumbuhana tinggi tanamannya tinggi selain itu karena faktor genetik. Menurut hal ini sesuasi dengan litelatur dimana menurut Sutrisna et al. (2013) perbedaan genetik tanaman terlihat jika varietas yang berbeda ditanam pada lingkungan yang sama dan akan menunjukan perbedaan yang nyata. Perbedaan antar varietas mulai nampak terutama pada pertumbuhan tinggi tanaman. Menurut Roesmarkam et al. (1985) ciri varietas sorgum unggul dilihat dari tinggi tanaman. Struktur tanaman sorgum yang tinggi sangat ideal untuk dikembangkan menjadi tanaman hijauan pakan (FAO 2002).

Tabel 1. Tinggi tanaman dan diameter batang empat varietas sorgum hybrid

\begin{tabular}{llllll}
\hline \multirow{2}{*}{ Pertumbuhan } & \multirow{2}{*}{ Jarak } & \multicolumn{4}{c}{ Varietas } \\
\cline { 3 - 6 } & & \multicolumn{1}{c}{$12 \mathrm{FS} 9006$} & $13 \mathrm{FB} 7001$ & $12 \mathrm{~S} 49001$ & Total \\
\hline Tinggi & $\mathrm{J} 1$ & $196,79 \pm 32,56$ & $175,23 \pm 19,90$ & $242,58 \pm 68,10$ & $188,52 \pm 19,83$ \\
tanaman 95 & $\mathrm{~J} 2$ & $190,20 \pm 32,71$ & $157,48 \pm 11,74$ & $218,98 \pm 34,23$ & $179,22 \pm 21,79$ \\
\cline { 2 - 6 } HST $(\mathrm{cm})$ & Total & $184,75 \pm 15,65^{\mathrm{ab}}$ & $163,85 \pm 13,09^{\mathrm{b}}$ & $203,05 \pm 12,02^{\mathrm{a}}$ & $183,87 \pm 20,20$ \\
\hline Diameter & $\mathrm{J} 1$ & $1,81 \pm 0,24$ & $1,70 \pm 0,17$ & $1,83 \pm 0,40$ & $1,87 \pm 0,22$ \\
Batang $(\mathrm{cm})$ & $\mathrm{J} 2$ & $1,75 \pm 0,11$ & $1,55 \pm 0,14$ & $1,83 \pm 0,28$ & $1,71 \pm 0,23$ \\
\cline { 2 - 6 } & Total & $1,83 \pm 0,16^{\mathrm{ab}}$ & $1,63 \pm 0,19^{\mathrm{b}}$ & $1,92 \pm 0,27^{\mathrm{a}}$ & $1,79 \pm 0,24$ \\
\hline
\end{tabular}

Keterangan: Superskrip (huruf kecil) pada kolom yang sama menunjukkan berbeda nyata $(\mathrm{P}<0,05)$

Interaksi antara varietas sorgum hybrid dan jarak tanam tidak berpengaruh terhadap diameter batang. Varietas sorgum berpengaruh nyata $(\mathrm{P}<0,05)$ terhadap diameter batang. Varietas sorgum hybrid memiliki diameter batang tertinggi diperoleh pada varietas $12 \mathrm{~S} 49006$ sebesar $1,92 \mathrm{~cm}$ dan 12FS9006 sebesar $1,83 \mathrm{~cm}$. Diameter batang terendah terdapat pada varietas 13FB70011 sebesar $1,63 \mathrm{~cm}$. Hal ini diduga bahwa varietas 12S49006 memiliki pertumbuhan tinggi tanaman yang tinggi. Menurut Garner et al., (1991) dan Sutrisna et al., (2013) perkembangan tanaman dengan baik mampu memanfaatkan jaringan pengangkut untuk melakukan pembelahan sel, sehingga terbentuk pembesaran batang. Perkembangan didapatkan dari ruas diantara daun-daun tanaman yang masih mendapatkan cahaya sehingga masih bisa berfotosintesis. Karbohidrat yang didapatkan dari hasil fotosintesis digunakan untuk menjadi energi selama proses pembelahan.

\section{Lebar, Panjang dan Jumlah Daun Varietas Sorgum Hybrid}

Lebar, panjang dan jumlah daun berpengaruh terhadap luasan bidang sehingga fotosintesis akan mempengaruhi produksi biomassa.

Tabel 2. Lebar, panjang, dan jumlah daun tanaman tiga varietas sorgum hybrid

\begin{tabular}{llllll}
\hline \multirow{2}{*}{ Pertumbuhan } & \multirow{2}{*}{ Jarak } & \multicolumn{4}{c}{ Varietas } \\
\cline { 3 - 6 } & & $12 \mathrm{FS} 9006$ & $13 \mathrm{FB} 7001$ & $12 \mathrm{~S} 49001$ & Total \\
\hline Lebar daun (cm) & $\mathrm{J} 1$ & $5,87 \pm 0,51$ & $6,55 \pm 0,59$ & $6,51 \pm 0,37$ & $6,31 \pm 0,56$ \\
& $\mathrm{~J} 2$ & $5,69 \pm 0,65$ & $6,04 \pm 0,38$ & $6,34 \pm 0,36$ & $6,02 \pm 0,52$ \\
\cline { 2 - 6 } & Total & $5,78 \pm 0,55^{\mathrm{b}}$ & $6,29 \pm 0,54^{\text {ab }}$ & $6,43 \pm 0,35^{\mathrm{a}}$ & \\
\hline Panjang daun (cm) & $\mathrm{J} 1$ & $81,84 \pm 6,91$ & $75,02 \pm 3,80$ & $90,39 \pm 5,82$ & $82,42 \pm 8,83$ \\
& $\mathrm{~J} 2$ & $79,75 \pm 4,79$ & $73,23 \pm 2,86$ & $85,07 \pm 7,78$ & $79,35 \pm 7,68$ \\
\cline { 2 - 6 } & Total & $80,80 \pm 6,45^{\text {ab }}$ & $74,12 \pm 3,72^{\mathrm{b}}$ & $87,73 \pm 7,88^{\mathrm{a}}$ & \\
\hline Jumlah daun (helai) & $\mathrm{J} 1$ & $15,33 \pm 3,56$ & $14,48 \pm 3,69$ & $16,65 \pm 4,11$ & $15,93 \pm 2,43$ \\
& $\mathrm{~J} 2$ & $14,83 \pm 1,43$ & $13,13 \pm 3,04$ & $15,70 \pm 3,46$ & $14,61 \pm 2,84$ \\
\cline { 2 - 6 } & Total & $15,40 \pm 2,12$ & $13,60 \pm 2,52$ & $16,81 \pm 2,59$ & \\
\hline
\end{tabular}

Keterangan : Superskrip (huruf kecil) pada baris yang sama menunjukkan berbeda nyata $(\mathrm{P}<0,05)$

Interaksi antara varietas sorgum hybrid dan jarak tanam tidak berpengaruh terhadap lebar daun. Varietas sorgum hybrid berpengaruh nyata $(\mathrm{P}<0,05)$ terhadap lebar daun. Daun terlebar pada penelitian terdapatpada varietas $12 \mathrm{~S} 49006(6,43 \mathrm{~cm})$ dan 13FB7001 (6,29 cm). Lebar daun terendah terdapat pada varietas $12 \mathrm{FS} 9006(5,78 \mathrm{~cm})$, hal ini diduga bahwa varietas 12S49006 memilliki pertumbuhan tinggi tanaman dan diameter batang yang lebar. Pertumbuhan dengan mencerminkan perubahan ukuran tanaman yang semakin membesar dan jumlah hasil tanaman. Pertambahan ukuran tanaman akan tumbuh secara keseluruhan sehingga akan menghasilkan pertambahan jumlah dan ukuran sel (Sitompul \& Guritno, 1995). lebar daun pada tanaman sorgum adalah 5-9 cm. Proses fotosintesis 
meningkat terlihat dari luas dan lebar daun (Ayub et al., 2002; Xie et al., 2012; Qu et al., 2014; Li et al., 2015).

Interaksi antara varietas sorgum hybrid dan jarak tanam tidak berpengaruh terhadap panjang daun. Varietas sorgum hybrid berpengaruh nyata $(\mathrm{P}<0,05)$ terhadap panjang daun. Daun terpanjang pada penelitian terdapat pada varietas $12 \mathrm{~S} 49006(87,73 \mathrm{~cm})$ dan varietas $12 \mathrm{FS} 9006(80,80 \mathrm{~cm})$. Varietas yang memiliki daun terpendek ada pada varietas 13FB7001 $(74,12 \mathrm{~cm})$. Hal ini diduga bahwa varietas 12S49006 memilliki pertumbuhan yang tinggi dan lebar daun yang lebar, selain itu faktor lingkungan. Menurut (Karyati et al., 2017) pertumbuhan tanaman akan memerlukan cahaya yang relatif banyak sehingga tanamanya cenderung mempunyai panjang daun dan lebar daun yang lebar.

Interaksi antara varietas sorgum hybrid dan jarak tanam tidak berpengaruh terhadap jumlah daun. Jumlah daun pengaruh nyata $(\mathrm{P}<0,05)$ oleh varietas. Jumlah daun terbanyak pada varietas 12S49006 (16 helai) dan 12FS9006 (15 helai). Varietas yang memiliki jumlah daun terendah pada varietas 13FB7001 (13 helai). Diduga pada varietas $12 S 49006$ memiliki lebar dan panjang daun tertinggi. Meningkatnya jumlah daun menunjukkan bahwa pertumbuhannya semakin baik karena jumlah dan luas daun merupakan proses fotosintesis dan fotosintat yang dihasilkan juga semakin meningkat (Rahayu et al., 2012; Sugianto et al., 2015). Jumlah daun sorgum bervariasi sekitar 7-40 helai tergantung pada varietasnya (Andriani \& Isnaini, 2013).

\section{KESIMPULAN}

Varietas 12S49001 memiliki pertumbuhan tanaman yang tinggi. Jarak tanam $25 \times 25 \mathrm{~cm}$ lebih tinggi dibandingkan dengan jarak tanam 25x40 cm. Varietas $12 S 49006$ merupakan varietas terbaik untuk dikembangkan sebagai pakan ternak.

\section{DAFTAR PUSTAKA}

Andriani, A. \& M. Isnaini.2013. Sorgum Teknologi Inovasi dan Pengembangan. IAARD Press. Jakarta.

Ayub, M., M.A. Nadeem, A. Tanveer, \& A. Husnain. 2002. Effect of different levels of nitrogen and harvesting times on the growth, yield and quality of sotghum fodder. Asian Journal of Plant Science 1:304-307.

Barcelos, C.A., R.N. Maeda, L.M.M. Santa Ann, \& N. Pereira. 2016. Sweet sorghum as a whole-crop feedstock for ethanol production. Biomass Bioenergy 94:4656.

Dwitama, G.M.D. 2017. Pertumbuhan Dan Produksi Beberapa Varietas Tanaman Sorgum Pakan Hijauan Hybrid Pada Sistem Monokultur. Fakultas Peternakan. Institut Pertanian Bogor. Bogor.

FAO. 2002. Sweet Sorgum in China. Spotlight 2000.

Gardner. F.P., RB. Pearce, \& R.L. Mitchell. 1991. Fisiologi Tanaman Budidaya. Terjemahan. UI Press. Jakarta.

Helena D. 2000. Pengaruh Jarak Tanam dalam Tumpangsari Kedelai ( Glycine Max (L.) Merril) dengan Sorgum (Sorgum bicolor (L.) Moench.) terhadap Pertumbuhan dan Produksi. Fakultas Pertanian Institut Pertanian Bogor. Bogor.

Karyati, J.R. Ransun, \& M. Syafrudin. 2017. Karakteristik Morfologis dan Anatomis Daun Tumbuhan Herba pada Paparan Cahaya Berbeda di Hutan Pendidikan Fakultas Kehutanan Universitas Mulawarman.. Jurnal Agrifor XVI (2):243-256.

Li, Y., P. Mao, W. Zhang, X. Wang, Y. You, H. Zhao, L. Zhai, \& G. Liu. 2015. Dynamic expression of the nutritive values in forage sorghum populations associated with white, green and brown midrid genotypes. Field Crops Research 184:112-122.

Rahayu, M., Samanhudi, \& Wartoyo. 2012. Uji adaptasi beberapa varietas sorgummanis di lahan kering wilayah Jawa Tengah dan Jawa Timur. Caraka Tani.27(1):53-62.

Qu, H., X.B. Liu, C.F. Dong, X.Y. Lu, \& Y.X. Shen. 2014. Field performance and nutritive value of sweet sorghum in eastern China. Field Crops Research 157:84-88.

Roesmarkam, S., Subandi, \& E. Muchlis. 1985. Hasil Penelitian Pemuliaan Sorgum. Bogor: Pusat Penelitian dan Pengembangan Pertanian. Bogor. 
Sirappa, M.P. 2003. Prospects for developing sorghum in Indonesia as an alternative commodity for food, feed, and industry. Agricultural Research and Development Journal 22:133-140.

Sitompul, S.M. \& B. Guritno. 1995. Analisis Pertumbuhan Tanaman. UGM Press. Yogyakarta.

Sugianto, Nurbaiti, \& Deviona. 2015. Variabilitas genetik dan heritabilitas karakter agronomis beberapa genotipe sorgum manis (Sorghum bicolor L. Moench) koleksi Batan. Jom Faperta.2(1):1-13.

Sutrisna, N., N. Sunandar, \& A. Zuabair. 2013. Uji adaptasi beberapa varietas sorgum (Sorghum bicolor L.)pada lahan kering di Kabupaten Ciamis, Jawa Barat. Jurnal Lahan Suboptimal 2(2):137-143.

Sriagtula, R., P.D.M.H. Karti, L. Abdullah, Supryanto, \& D.A. Astuti. 2016. Growth biomass and nutrient production of brown midrib sorghum mutant lines at different harvest time. Pakistan Journal of Nutrition 15:524-531.

Syukur, M., S. Sujiprihati, \& R. Yunianti. 2012. Teknik Pemuliaan Tanaman. Penebar Swadaya. Jakarta.

Xie, T., P. Sue, L. Shan, \& J. Mao. 2012. Yield, quality and irrigation water use efficiency of sweet sorghum (Sorghum bicolor (Linn.) Moench) under different land types in arid regions. AJCS 6(1):10-16. 